\title{
Follow-up Research of the High Vocational Nursing Students' Self-esteem and Their Coping Style*
}

\author{
Zhili $\mathrm{Bi}^{1}$, Lijuan Meng ${ }^{2}$, and Xuemei $\mathrm{Liu}^{3}$ \\ ${ }^{1)}$ Nursing School, Binzhou Polytechnic, Binzhou, Shandong, China (beelili@ 126.com) \\ ${ }^{2)}$ Department of Social Sciences, Binzhou Polytechnic, Binzhou, Shandong, China (menglijuan626@126.com) \\ ${ }^{3)}$ Nursing School, Binzhou Polytechnic, Binzhou, Shandong, China (liuxuemei0927@163.com)
}

\begin{abstract}
In 2013, we continue to use the Self-esteem Scale (SES) and Simplified Coping Style Questionnaire. We random surveyed for grade 2012 students in Nursing College of Binzhou Polytechnic. The proportion of complete questionnaires is 99.82\%. As a result, the Self-esteem Scale score was $32.57 \pm 3.40,2.15 \pm 0.39$ score of positive coping, negative coping style score $1.29 \pm 0.48$. We compared the students' questionnaire scores of different gender, who from the city or the countryside, and family economic status. We analyses the correlation of self-esteem and coping styles, and compared the results of the investigation in 2012. The purpose of this study is to provide the basis for students' psychological health education of higher vocational nursing.
\end{abstract}

Keywords—vocational school, nursing speciality, Self-esteem Scale, coping style, students with financial difficulties

\section{高职护生自尊与应对方式跟踪调查研究}

\author{
毕智丽 $^{1}$ 孟丽娟 $^{2}$ 刘雪梅 ${ }^{1}$ \\ 1) 滨州职业学院护理学院, 滨州, 山东, 中国 \\ 2) 滨州职业学院社会科学部, 滨州, 山东, 中国
}

摘 要 2013 年继续使用自尊量表 (SES) 和简易应对方式问卷, 面向滨州职业学院护理学院 2012 级高职学生进行随机问卷调查, 问卷合格率 $99.82 \%$ 。结果自尊量表得分 $32.57 \pm 3.40$, 积极应对方式得分 $2.15 \pm 0.39$, 消极应对方式得分 $1.29 \pm 0.48$ 。对比不同性别、生 源地性质和家庭经济状况学生问卷得分, 对自尊与应对方式的相关性进行了分析, 并将贫困高职护生量表结果与 2012 年调查结果进行 了比较。为高职护生心理健康教育工作的开展提供了依据。

关键词 高职, 护理, 自尊量表, 应对方式, 贫困生

\section{1. 前言}

2012 年 10 月, 我们面向滨州职业学院护理专业高职学 生, 开展了自尊与应对方式的问卷调查, 研究结果成文发 表 $^{[1]}$, 为了对调查结果进行验证和纵向比较, 考察 1 年来学 生自尊水平和应对方式的变化, 2013 年 10 月, 我们面向 2012 级高职护生再次开展了相同问卷的调查。为了加强横 向比较, 统计信息更加全面, 我们增加了对非贫困生的调 查, 并区分了调查对象的性别和生源地性质。数据统计和 分析方法同前。

\section{2. 研究对象}

面向 12 级护理专业高职学生随机发放问卷 565 份, 回 收合格问卷 564 份, 合格率 $99.82 \%$ 。调查对象年龄 $20.07 \pm 0.63$, 其中男护生 36 人 $(6.38 \%)$, 女护生 528 人 (93.62\%); 城镇生源 135 人 ( $23.94 \%)$, 农村生源 429 人 $(76.06 \%)$; 非贫困生 416 人 $(73.76 \%)$, 贫困生 148 人 $(26.24 \%)$ 。贫困护生中男生 4 人 $(2.70 \%)$, 女生 144 人 $(97.30 \%)$; 城镇 15 人 ( $10.14 \%)$, 农村 133 人 ( $89.86 \%)$; 其中未受资助 32 人 $(21.62 \%)$, 荣获国家励志奖学金 39 人

*山东省高等学校学生教育与管理研究项目立项课题（编号：2013C032）

作者简介: 毕智丽 (1979-), 女, 河北沧州人, 讲师, 硕研。滨州职业学院护理学院辅导员, 国家二级心理咨询师。

电话: 13589738725 , 地址: 滨州市滨州职业学院护理学院, 邮编: 256603 
( $26.35 \%)$, 受助国家一档助学金 17 人 $(11.49 \%)$, 二档 33 人 $(22.30 \%)$, 三档 27 人 $(18.24 \%)$ 。

\section{3. 结果与分析}

\section{1 数据统计}

对 2013 年调查数据进行整理, 结果见表 1 。

结果显示 12 级高职护生自尊水平总体较高[2-4]。区分 性别、生源地性质、家庭经济状况, 对 12 级高职护生的自
尊水平、积极应对和消极应对维度得分分别进行比较, 结 果自尊和积极应对没有明显差异 $(\mathrm{p}>0.05)$, 水平相近。而 消极应对维度情况, 不同生源地性质的差异显著 $(0.01<\mathrm{p}$ $<0.05)$, 不同性别和家庭经济状况的差异极显著 $(\mathrm{p}<$ 0.01 )。这与面向不同专业进行的相关调查结论一致 ${ }^{[5]}$ 。区 分性别和生源地性质，对 12 级贫困高职护生的自尊水平、 积极应对和消极应对情况分别进行比较, 结果仅有不同性 别的自尊水平存在显著差异 $(0.01<\mathrm{p}<0.05)$, 其他比较均 差异不明显 $(\mathrm{p}>0.05)$, 这可能与贫困男护生样本过小有关。

表 1 高职护生自尊量表和简易应对方式问卷得分

\begin{tabular}{|c|c|c|c|c|}
\hline & & 自尊量表分 & 积极应对维度分 & 消极应对维度分 \\
\hline \multicolumn{2}{|c|}{12 级高职护生 } & $32.57 \pm 3.40$ & $2.15 \pm 0.39$ & $1.29 \pm 0.48$ \\
\hline \multirow{4}{*}{ 性别 } & 男 & $31.67 \pm 3.59$ & $2.16 \pm 0.48$ & $1.71 \pm 0.58$ \\
\hline & 女 & $32.63 \pm 3.38$ & $2.15 \pm 0.38$ & $1.26 \pm 0.47$ \\
\hline & $\mathrm{t}$ 值 & -1.094 & 0.099 & 4.36 \\
\hline & $\mathrm{P}$ & 0.140 & 0.461 & $7.76 \times 10^{-6}$ \\
\hline \multirow{4}{*}{ 生源地性质 } & 城镇 & $32.59 \pm 3.55$ & $2.14 \pm 0.41$ & $1.39 \pm 0.50$ \\
\hline & 农村 & $32.56 \pm 3.36$ & $2.15 \pm 0.38$ & $1.26 \pm 0.47$ \\
\hline & $\mathrm{t}$ 值 & 0.062 & -0.051 & 2.196 \\
\hline & $\mathrm{P}$ & 0.475 & 0.479 & 0.014 \\
\hline \multirow{4}{*}{ 家庭经济状况 } & 非贫困生 & $32.58 \pm 3.53$ & $2.15 \pm 0.39$ & $1.33 \pm 0.48$ \\
\hline & 贫困生 & $32.51 \pm 3.04$ & $2.15 \pm 0.38$ & $1.16 \pm 0.46$ \\
\hline & $\mathrm{t}$ 值 & 0.193 & -0.024 & 2.95 \\
\hline & $\mathrm{P}$ & 0.424 & 0.491 & 0.002 \\
\hline \multirow{11}{*}{ 贫困生 } & 一年级 & $32.27 \pm 2.92$ & $2.08 \pm 0.33$ & $1.02 \pm 0.38$ \\
\hline & t 值 & -0.567 & -1.261 & -2.313 \\
\hline & $\mathrm{P}$ & 0.286 & 0.104 & 0.011 \\
\hline & 男 & $36.25 \pm 1.38$ & $2.17 \pm 0.29$ & $1.56 \pm 0.50$ \\
\hline & 女 & $32.41 \pm 3.02$ & $2.15 \pm 0.38$ & $1.15 \pm 0.46$ \\
\hline & $\mathrm{t}$ 值 & 2.121 & 0.077 & 1.414 \\
\hline & $\mathrm{P}$ & 0.018 & 0.469 & 0.080 \\
\hline & 城镇 & $31.73 \pm 3.01$ & $2.31 \pm 0.29$ & $1.36 \pm 0.48$ \\
\hline & 农村 & $32.60 \pm 3.02$ & $2.13 \pm 0.39$ & $1.14 \pm 0.45$ \\
\hline & $\mathrm{t}$ 值 & -0.881 & 1.347 & 1.394 \\
\hline & $\mathrm{P}$ & 0.190 & 0.090 & 0.083 \\
\hline
\end{tabular}

将 2013 年 12 级贫困高职护生的自尊、积极应对、消 极应对得分, 与 2012 年该年级相关调查数据 ${ }^{[1]}$ 进行比较, 结果自尊和积极应对得分差异不明显 ( $p>0.05$ ), 消极应对 得分差异显著 $(0.01<\mathrm{p}<0.05)$, 即 12 级贫困高职护生在 2013 年比 2012 年, 对消极应对方式的选择有明显增加, 除 了“试图休息或休假, 暂时把问题（烦恼）抛开”, 其它消 极应对方式的得分都有所增加。这可能是因为护生们的应 对方式还不稳定, 在环境的影响下发展变化着。
3.2 高职生应对方式分析

\section{2 .1 高职生常用应对方式}

对贫困高职护生常用应对方式的得分进行排序, 进行 2 年间的变化比较, 并与非贫困生比较, 结果见表 2 。

“自己安慰自己”是唯一在 2 次调查中都进入排位前 10 的消极应对方式, 其他排位在不同的积极应对方式之间变 化, 对“坚持自己的理想, 为自己想得到的斗争”的选择在 2 
年间的变化最大, 2012 年得分 $1.89 \pm 0.75,2013$ 年得分 $2.39 \pm 0.67, \mathrm{p}<0.01$ 差异极显著, 这与 2012 年同时调查的 11、12 两个年级的差异情况基本一致 ${ }^{[1]}$, 说明滨职对高职 护生的心理健康教育和相关课程的开设, 确实有助于引导
高职护生树立理想、坚定信心。

分别对高职护生选择“经常采取”的积极和消极应对方 式的人数比例进行了统计, 结果见表 3 。

表 2 高职护生常用应对方式

\begin{tabular}{lcccccc}
\hline \multicolumn{1}{c}{ 应对方式 } & \multicolumn{3}{c}{ 贫困生 } & \multicolumn{2}{c}{ 非贫困生 } \\
& 2012 年得分 & 排序 & 2013 年得分 & 排序 & 2013 年得分 & 排序 \\
\hline 尽量看到事物好的一面 & $2.45 \pm 0.62$ & 1 & $2.47 \pm 0.64$ & 1 & $2.39 \pm 0.67$ & 1 \\
与人交谈, 倾诉内心烦恼 & $2.27 \pm 0.68$ & 2 & $2.33 \pm 0.63$ & 4 & $2.26 \pm 0.68$ & 4 \\
尽量克制自己的失望、悔恨、悲伤和愤怒 & $2.26 \pm 0.66$ & 3 & $2.16 \pm 0.63$ & 6 & $2.12 \pm 0.65$ & 7 \\
改变自己的想法, 重新发现生活中什么重要 & $2.25 \pm 0.71$ & 4 & $2.34 \pm 0.65$ & 3 & $2.28 \pm 0.66$ & 3 \\
向亲戚朋友或同学寻求建议 & $2.21 \pm 0.64$ & 5 & $2.14 \pm 0.58$ & 7 & $2.19 \pm 0.69$ & 6 \\
寻求业余爱好, 积极参加文体活动 & $2.19 \pm 0.65$ & 6 & $2.11 \pm 0.71$ & 8 & $2.07 \pm 0.67$ & 9 \\
找出几种不同的解决问题的方法 & $2.11 \pm 0.61$ & 8 & $2.23 \pm 0.61$ & 5 & $2.26 \pm 0.62$ & 5 \\
自己安慰自己 $(\mathrm{N})$ & $1.93 \pm 0.72$ & 9 & $2.02 \pm 0.62$ & 9 & $2.01 \pm 0.68$ & 10 \\
坚持自己的理想, 为自己想得到的斗争 & $1.89 \pm 0.75$ & 11 & $2.39 \pm 0.67$ & 2 & $2.28 \pm 0.67$ & 2 \\
改变原来的一些做法或自己的一些问题 & $1.75 \pm 0.69$ & 13 & $1.99 \pm 0.56$ & 10 & $2.09 \pm 0.56$ & 8 \\
\hline
\end{tabular}

表 3 高职护生“经常采取”的积极和消极应对方式

\begin{tabular}{|c|c|c|c|}
\hline \multirow{2}{*}{ 应对方式条目 } & \multicolumn{2}{|c|}{ 贫困生 } & \multirow{2}{*}{ 非贫困生 } \\
\hline & 2012 年 & 2013 年 & \\
\hline \multicolumn{4}{|l|}{ 积极应对方式 } \\
\hline 尽量看到事物好的一面 & $56.85 \%$ & $60.81 \%$ & $54.57 \%$ \\
\hline 改变自己的想法, 重新发现生活中什么重要 & $47.26 \%$ & $49.32 \%$ & $45.91 \%$ \\
\hline 与人交谈，倾诉内心烦恼 & $46.58 \%$ & $47.30 \%$ & $46.39 \%$ \\
\hline 尽量看到事物好的一面 & $44.52 \%$ & $37.16 \%$ & $36.78 \%$ \\
\hline 向亲戚朋友或同学寻求建议 & $40.41 \%$ & $33.78 \%$ & $42.55 \%$ \\
\hline 坚持自己的理想, 为自己想得到的斗争 & $30.14 \%$ & $54.73 \%$ & $46.63 \%$ \\
\hline 找出几种不同的解决问题的方法 & $34.25 \%$ & $39.86 \%$ & $42.07 \%$ \\
\hline \multicolumn{4}{|l|}{ 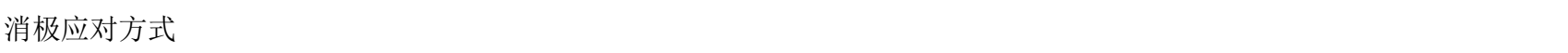 } \\
\hline 自己安慰自己 & $31.51 \%$ & $31.76 \%$ & $34.13 \%$ \\
\hline 试图休息或休假, 暂时把问题（烦恼）抛开 & $26.03 \%$ & $25.68 \%$ & $32.93 \%$ \\
\hline 接受现实，因为没有其它办法 & $10.27 \%$ & $7.43 \%$ & $12.98 \%$ \\
\hline 试图忘记整个事情 & $8.22 \%$ & $8.11 \%$ & $12.02 \%$ \\
\hline 幻想可能会发生某种奇迹改变现状 & $4.11 \%$ & $8.11 \%$ & $12.50 \%$ \\
\hline
\end{tabular}

对消极应对方式“经常采取”的比例, 在不同经济状况 高职护生之间, 及在贫困生 2 年间, 都无明显差别; 而积 极应对方式出现了一些变化, “经常采取”比例前 5 位的积 极应对方式存在较大差别, 2013 年高职护生更多选择了“坚 持自己的理想, 为自己想得到的斗争”和“找出几种不同的 解决问题的方法”, 这是他们随着年龄的增长、心智的成熟, 更多有了自己的理想、规划, 及更多学会了辩证思考, 懂 得多途径解决问题。这可能与滨职学生心理健康教育的成 功开展, 与《大学生心理素质训练》、《大学生就业与创业
指导》、《解决问题能力》等课程的开设有关。

\subsection{2 高职护生应对倾向分析}

对 12 级高职护生积极应对和消极应对倾向的人数、所 占比例, 区别不同性别、生源地性质、家庭经济状况高职 护生积极或消极应对倾向的人数, 及在各自群体中所占的 比例分别进行了统计, 结果见表 4。结果与另一研究相似 [5], 即更大比例的女生比男生能够选择积极应对方式; 农村生 源的高职护生选择积极应对方式的比例更大; 贫困生选择 
积极应对方式的比例比非贫困生大。

将 12 级贫困高职护生积极和消极应对倾向进行 2 年间 的比较, 结果贫困高职护生在 2013 年比 2012 年, 消极应 对倾向有所增加, 与前文应对方式的分析结果一致。

\section{3 高职护生自尊与应对方式的相关研究}

将滨职 12 级高职护生按其自尊量表得分分出 2 个极端 组, 比平均分 (32.57) 低 1 个标准差 (3.40) 以上的为低 分组, 高 1 个标准差以上的为高分组, 即自尊量表 $\leq 29$ 分为
低分组, $\geq 36$ 分为高分组。分别统计 2 个极端组中分布的不 同性别、生源地性质、家庭经济状况的人数, 及其在各自 类别中的比例, 结果见表 5 。

对比 2 个极端组简易应对方式问卷得分, 结果积极应 对方式 $\mathrm{p}<0.01$, 自尊高分组 $2.43 \pm 0.31$ 高于自尊低分组 $1.92 \pm 0.41$, 差异极显著; 消极应对方式 $0.01<\mathrm{p}<0.05$, 自 尊低分组 $1.48 \pm 0.43$, 高于自尊高分组 $1.32 \pm 0.58$, 差异显著。 这与另一研究 ${ }^{[5]}$ 和马利军等运用肖计划《应对方式问卷》所 做调研结论一致[4]。

表 4 高职护生应对倾向

\begin{tabular}{|c|c|c|c|c|c|c|}
\hline & & & \multicolumn{2}{|c|}{ 积极应对倾向 } & \multicolumn{2}{|c|}{ 消极应对倾向 } \\
\hline & & & 人数 & 比例 & 人数 & 比例 \\
\hline \multicolumn{3}{|c|}{12 级高职护生 } & 460 & $81.56 \%$ & 104 & $18.44 \%$ \\
\hline \multirow{2}{*}{\multicolumn{2}{|c|}{ 性别 }} & 男 & 24 & $66.67 \%$ & 12 & $33.33 \%$ \\
\hline & & 女 & 436 & $82.58 \%$ & 92 & $17.42 \%$ \\
\hline \multirow{2}{*}{\multicolumn{2}{|c|}{ 生源地性质 }} & 城镇 & 106 & $78.52 \%$ & 29 & $21.48 \%$ \\
\hline & & 农村 & 354 & $82.52 \%$ & 75 & $17.48 \%$ \\
\hline \multirow{2}{*}{\multicolumn{2}{|c|}{ 家庭经济状况 }} & 非贫困生 & 332 & $79.81 \%$ & 84 & $20.19 \%$ \\
\hline & & 贫困生 & 128 & $86.49 \%$ & 20 & $13.51 \%$ \\
\hline \multirow{5}{*}{ 贫困生 } & & & 130 & $89.04 \%$ & 16 & $10.96 \%$ \\
\hline & \multirow{4}{*}{ 二年级 } & 男 & 4 & $100 \%$ & 0 & $0.00 \%$ \\
\hline & & 女 & 124 & $86.11 \%$ & 20 & $13.89 \%$ \\
\hline & & 城镇 & 13 & $86.67 \%$ & 2 & $13.33 \%$ \\
\hline & & 农村 & 115 & $86.47 \%$ & 18 & $13.53 \%$ \\
\hline
\end{tabular}

表 5 自尊高分组与低分组各类学生比例

\begin{tabular}{ccccccccc}
\hline & & 总 & 男 & 女 & 城镇 & 农村 & 非贫困生 & 贫困生 \\
\hline \multirow{2}{*}{ 高分组 } & 人数 & 138 & 8 & 130 & 35 & 103 & 107 & 31 \\
& 比例 & $24.47 \%$ & $22.22 \%$ & $24.62 \%$ & $25.93 \%$ & $24.01 \%$ & $25.72 \%$ & $20.95 \%$ \\
\multirow{2}{*}{ 低分组 } & 人数 & 123 & 9 & 114 & 29 & 94 & 91 & 32 \\
& 比例 & $21.81 \%$ & $25.00 \%$ & $21.59 \%$ & $21.48 \%$ & $21.91 \%$ & $21.88 \%$ & $21.62 \%$ \\
\hline
\end{tabular}

\section{4. 讨论}

滨职高职护生自尊与应对方式状况整体较好。横向比 较研究与跟踪调查研究, 都显示自尊与积极应对方式整体 情况与发展趋势较好, 消极应对在城乡差别、经济状况差 别、发展变化趋势方面都不同程度呈现问题, 需要进一步 调查以发现原因, 以便在校园环境、文化教育、学生管理、 心理健康教育等各方面引导学生, 减少其在应激时选择消 极应对方式, 更积极、成熟地适应环境、综合发展。

\section{参考文献(References)}

[1] Zhili Bi, "Correlation study about the self-esteem of impoverished high vocational nursing students and their coping styles," 2014 4th International Conference on Applied Social Science(ICASS 2014).

[2] Xiaoyang Dai, etc, Common psychological assessment handbook. People's Military Medical Press, vol. 7, pp. 251-253, 2010.

[3] Xiangqian Han, Bo Jiang and Jiayan Tang, "Self-esteem scale used in the process of problems and suggestions," Chinese Journal of Behavioral Medical and Brain Science, vol. 14, no. 8, pp. 763, 2005.

[4] Lijun Ma and Huiping Tan, "Correlation between students' self-esteem and coping style of medical college poverty," Soft Science of Health, vol. 23, no. 6, pp. 627-629, 2009.

[5] Zhili Bi, "The investigation and analysis of self-esteem and coping style of high vocational students," 2014 International Conference on Social, Education and Sports(ICSES 2014). 